\title{
Microstructure Evolution and Properties of Friction Stir Welding Joint for 6082-T6 Aluminum Alloy
}

\author{
Liangliang Zhang ${ }^{\circledR}$, Xijing Wang ${ }^{a, b, *}$ \\ ${ }^{a}$ State Key Laboratory of Advanced Processing and Recycling of Non-ferrous Metals,Lanzhou University \\ of Technology, Lanzhou 730050, China \\ ${ }^{b}$ School of Materials Science and Engineering, Lanzhou University of Technology, Lanzhou 730050, \\ China
}

Received: April 17, 2018; Revised: July 10, 2018; Accepted: July 23, 2018

\begin{abstract}
To investigate the evolution of grain morphologies, grain boundary features, and dislocation structure in upper part of nugget zone during friction stir welding of 6082-T6 aluminum alloys, electron backscattered diffraction and transmission electron microscope techniques were employed. The results showed that the metal on retreating side of the weld zone produced thermoplastic deformation during the welding process. The substructure of the lamellar dislocation wall formed at retreating side. Motivated by the welding thermal cycle, geometric dynamic recrystallization occurred in the substructure of the lamellar grains, leading to the lamellar array of grains. Discontinuous dynamic recrystallization occurred in the lamellar grain, leading the grain to be arranged in a "necklace" form. Simultaneously, the coarse grain of base material was refined. Due to the inhomogenous distribution of stress during the welding process, the alternating presence of large grain and small grain regions on advancing side took place. During the process of welding joint tensile, the fracture results from dislocation piling-up at the $\mathrm{Mg}_{2} \mathrm{Si}$ interface in large grains with a (111)[T10] orientation. Thus, the advancing side becomes the weakest part of the mechanical properties in the welding joint,the tensile strength of the joint was $275 \mathrm{MPa}$ with a break elongation of $6 \%$.
\end{abstract}

Keywords: 6082-T6 aluminum alloy, friction stir welding, dynamic recrystallization, EBSD.

\section{Introduction}

The central goal of welding is to establish a link between the welding process parameters and joint performance, and the material microstructure determines its performance. Therefore, it is particularly important to research the relationship between the microstructure evolution law of welded joints and their properties. The 6082-T6 aluminum alloy can be used as a new lightweight material instead of traditional steel material for application in the transportation and structural engineering industry, and can reduce weight and achieve energy-saving and emission-reduction ${ }^{1}$. However, when the traditional fusion welding process is used to weld aluminum alloy, it is easy to produce pores, hot cracks and other defects. Friction stir welding (FSW), as a new solid-state connection technology, has the advantages of small welding deformation, small residual stress and no solidification and liquation cracking ${ }^{2}$. High quality welding joint of aluminum alloy can also be obtained by $\mathrm{FSW}^{3}$.

In the process of friction stir welding, the weld metal has undergoes plastic deformation at high temperature ${ }^{4}$. The plastic deformation of face-centered cubic (FCC) metals is realized by the movement and interaction of dislocations in the slip process, during which the slip surface and the slip direction rotate along a certain direction until reaching a

*e-mail:wangxj@lut.cn stable orientation. Thus, the grain of the FSW joint appears in its preferred orientation; at the same time, the precipitation of the alloy phase also affects the movement of dislocations.

Many scholars ${ }^{5-7}$ have applied the electron backscattered diffraction (EBSD) to study the law of grain orientation evolution during the welding process. Suhuddin et al. ${ }^{6}$ observed that the $\left\{\begin{array}{lllll}1 & 1 & 2\end{array}\right\}<1 \quad 10>$ shear texture formed around the keyhole given the shear stress introduced by the stirred pin, while, due to the nugget area undergoing static heat treatment, the $\left\{\begin{array}{llllll}1 & 0 & 0\end{array}<<1 \quad 0 \quad 0>\right.$ cubic texture dominates in the far away keyhole area. Some scholars ${ }^{8}$ have used transmission electron microscope (TEM) techniques to study the change trend of dislocations in the grain and the distribution of the precipitates during the welding process.

Besides, some scholars have studied the temperature field distribution during the FSW wielding process of 6082 aluminum alloy. Vermaa et al. ${ }^{9}$ studied the temperature field distribution in the FSW process of 6082 aluminum alloy and the results showed that the temperature on the advancing side of the welding nucleus was higher than the retreating side.Tamadon et al. ${ }^{10}$ discussed the evolution law of microstructure for the A6082-T6 aluminum alloy during FSW by the metallographic etchants method and the results showed that the coarse grain of the base material was refined with its morphology evolving from columnar grain to the equiaxed grain of the weld nucleus. Moreover, the etchants 
also clearly showed the polycrystalline structure, microflow patterns, and the incoherent interface around the inclusion defects. The electrochemical corrosion behaviors of FSW and mixed inert gas welding (MIG) joints of 6082 aluminum alloy and base material were investigated in a solution of 0.2 $\mathrm{mol} / \mathrm{L} \mathrm{NaHSO}_{3}$ and $0.6 \mathrm{~mol} / \mathrm{L} \mathrm{NaCl}$ using the potentiodynamic polarization curve, electrochemical impedance spectroscopy (EIS) and scanning electron microscopy (SEM) observation ${ }^{11}$. These results showed that the corrosion rate of the FSW joint was less than those of the MIG joint and the base material. EIS Nyquist loops indicated that an inductive arc existed inthe complex plane. SEM observations showed that a few shallow pits occurinthe surface of the FSW joint; however, a large number of deeper pits appear on the surface of the base materials and MIG joint.

Compared to other 6000 series aluminum alloys, 6082 has a higher strength and better corrosion resistance due to the presence of a higher amount of manganese. FSW is the most effective connection of aluminum alloy, so it is very important to study the FSW process of the 6082-T6 aluminum alloy.

In this paper, the 6082-T6 aluminum alloy processed by FSW was studied. The grain orientation, dislocation structure, and the distribution of precipitated phases on the upper surface of the nugget were analyzed by EBSD and TEM. This provided a theoretical basis for the wide application of 6082-T6 aluminum alloy.

\section{Materials and Methods}

The base material was a 6082-T6 aluminum alloy with the size $100 \mathrm{~mm} \times 50 \mathrm{~mm} \times 2 \mathrm{~mm}$, and its composition is shown in Table 1(The data were obtained by EDS (Oxford Instruments, Oxford, UK)).

Table 1. Nominal compositions of the 6082 aluminum alloy employed in this work. (wt,\%)

\begin{tabular}{lccccccc}
\hline $\mathrm{Si}$ & $\mathrm{Mg}$ & $\mathrm{Cu}$ & $\mathrm{Ti}$ & $\mathrm{Fe}$ & $\mathrm{Cr}$ & $\mathrm{Zn}$ & $\mathrm{Al}$ \\
\hline 0.97 & 0.67 & 0.07 & 0.01 & 0.37 & 0.01 & 0.06 & $\mathrm{Bal}$ \\
\hline
\end{tabular}

During the welding process, a cylindrical shoulder and a profiled pin were used to join along the rolling direction. The diameter of the shoulder was $10 \mathrm{~mm}$; the diameter of the pin was $2 \mathrm{~mm}$ and the length of pin was $1.8 \mathrm{~mm}$, as shown in Figure 1.

The optimal welding parameters were obtained by the orthogonal test method EBSD and TEM tests were performed for the joints under the optimal parameters to discuss the evolution law of structure during the FSW process. The optimum process parameters were as follows: the welding speed was $80 \mathrm{~mm} / \mathrm{min}$; the rotation speed was $1000 \mathrm{r} /$ min; the inclination angle of tool was $3^{\circ}$ and the additional compression of the shoulder was $0.1 \mathrm{~mm}$. As the tool walked $80 \mathrm{~mm}$, the welding stopped immediately and the dynamic organization was frozen by the ice water mixture. According to the flow law of viscoplasticity metal during the FSW process, the viscoplasticity metal flow first enters the retreating side and finally reaches the advancing side. The flow state of the viscoplastic metal in the nugget zone is controlled by the shoulder. The material flow determines the preferred orientation of the grain in the nugget zone with little change to the texture along the thickness direction. In this paper, the upper surface of the nugget zone was selected as the research object to analyze grain orientation and dislocation structure ${ }^{12}$.

Therefore, as shown in Figure 2, region 1 was located at the retreating side of the nugget, and region 2 was located in the advancing side of the nugget. EBSD and TEM samples

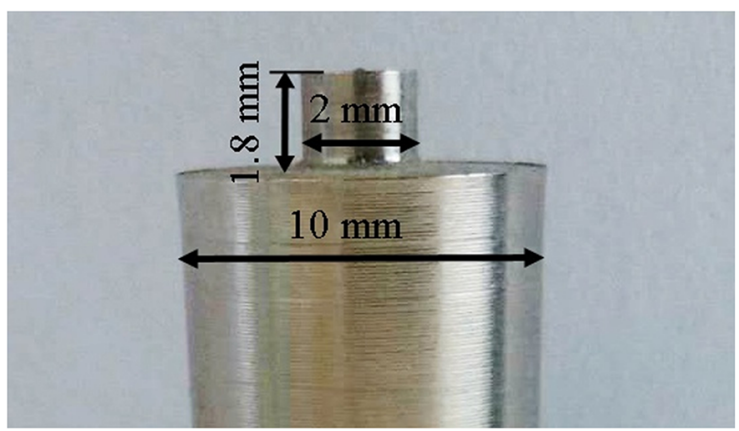

Figure 1. Photo of welding tool

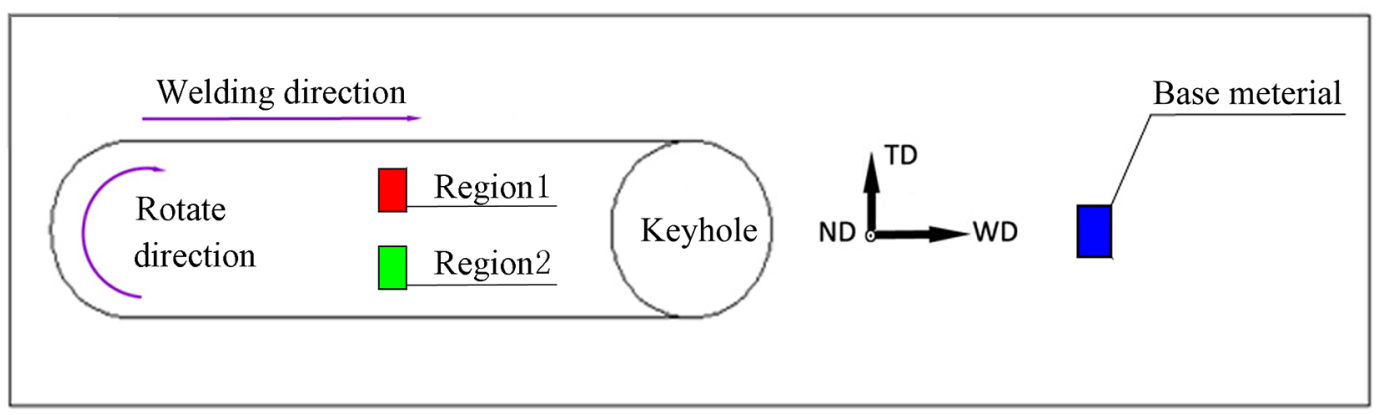

Figure 2. Welding direction and rotation direction of shoulder and sample location diagram of electron backscattered diffraction (EBSD) and transmission electron microscope (TEM) 
were cut and intercepted by wire-electrode cutting in the base material and nugget zone.

The upper surface of the EBSD sample was coarsely ground with sandpaper, and after mechanical polishing, the surface of the sample was subjected to electrolytic polishing in a $10 \%$ perchloric acid anhydrous ethanol solution with a polishing voltage of $20 \mathrm{~V}$, liquid temperature of $-20^{\circ} \mathrm{C}$ and a polishing time of $40 \mathrm{~s}$. A field emission scanning electron microscope (Quanta 450 FEG) with EBSD probe (AztecXMax80) and Channel 5 orientation analysis system was used to conduct the EBSD test at a voltage of $20 \mathrm{kV}$. In the analysis process, the reference coordinate system is shown in Figure 2. In the welding direction (WD), transverse direction (TD) and normal direction (ND), the grain orientation were expressed in the form of $(\mathrm{h} \mathrm{k} \mathrm{l})[(\mathrm{u} \mathrm{v} \mathrm{w})]$ where $(\mathrm{h} \mathrm{k} \mathrm{l})$ is perpendicular to the crystal plane of ND, and $[(\mathrm{u} v \mathrm{w})]$ is parallel to the direction of the WD crystal orientation. The grain boundary with amisorientation of $2^{\circ} \sim 15^{\circ}$ was defined as a small-angle grain boundary, and when larger than $15^{\circ}$, a large-angle grain boundary was defined. The average grain size was calculated by the equivalent diameter method.

The uppe and lower surface of the TEM samples were coarsely ground to $40 \mu \mathrm{m}$ with a series of sandpapers and thinned to perforation on a double spray electrolytic thinning apparatus. The surface of sample was subjected to electrolytic polishing in a $10 \%$ perchloric acid anhydrous ethanol solution with liquid temperature below $-20^{\circ} \mathrm{C}$. TEM (JEM-2010) was used to observe the microstructure of the joints in different regions. The size of the tensile specimen is shown in Figure 3, where the weld was located at the center of the tensile specimen. At room temperature, tensile tests on three parallel specimens of base metal and weld were carried out on AG-10TA universal tensile machine with a rate of $0.2 \mathrm{~mm} / \mathrm{min}$, and the average value of the tensile tests was taken. Next, the fracture morphology was observed by
QUANTA FEG 450 heat field emission scanning electron microscope (SEM).

\section{Results and Discussion}

\subsection{Microstructure of basematerial}

The grain characteristics of the upper surface of the base material were analyzed through the EBSD technique and grain morphology was revealed by the orientation imaging method. After the T6 heattreatment, the 6082 aluminum alloy rolled plate experienced complete recrystallization with some grains growing more seriously ${ }^{13}$, as shown in Figure 4a. However, the flat grain structure after rolling treatment still retained an average grain size of $25 \mu \mathrm{m}$. As shown in Figure 4b, the grain misorientation is represented by the histogram; misorientation is close to random misorientation with no obvious preferred orientation. At the same time, the precipitation phase distribution in the base material was analyzed by TEM, and the results ${ }^{14,15}$ showed that there was needle-like precipitate $\beta^{\prime \prime}\left(\mathrm{Mg}_{5} \mathrm{Si}_{6}\right.$, bottom center monoclinic structure) as shown in Figure $4 \mathrm{c}$ with the white arrow. The corresponding electoral electron diffraction pattern for $\beta^{\prime \prime}$ is shown in Figure $4 d$. The 6082 aluminum alloy after T6heat treatment still had a $\beta$ phase $\left(\mathrm{Mg}_{2} \mathrm{Si}\right.$, Face centered cubic structure) as shown in Figure $4 \mathrm{c}$ with the black arrow, its corresponding electoral electron diffraction pattern is shown in Figure 4e.

\subsection{Macrostructure of nugget}

Under the optimum welding parameters, a high quality welding joint was obtained, with good surface forming and no defects like flash, etc. As shown in Figure 5a, the grains on the retreating side(RS) of the nugget elongated, as displayed in Figure 5b. Due to the good corrosion resistance of the 6082

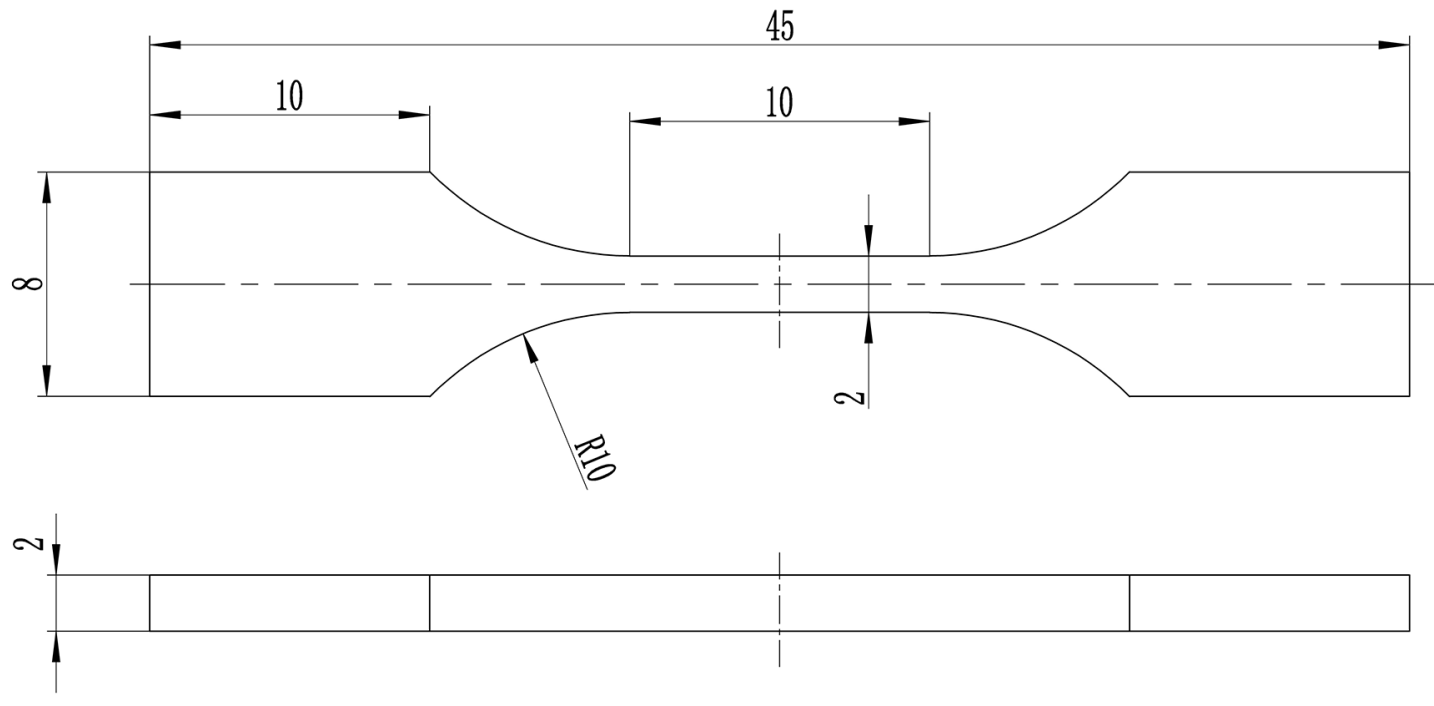

Figure 3. Schematic diagram of the tensile specimen 

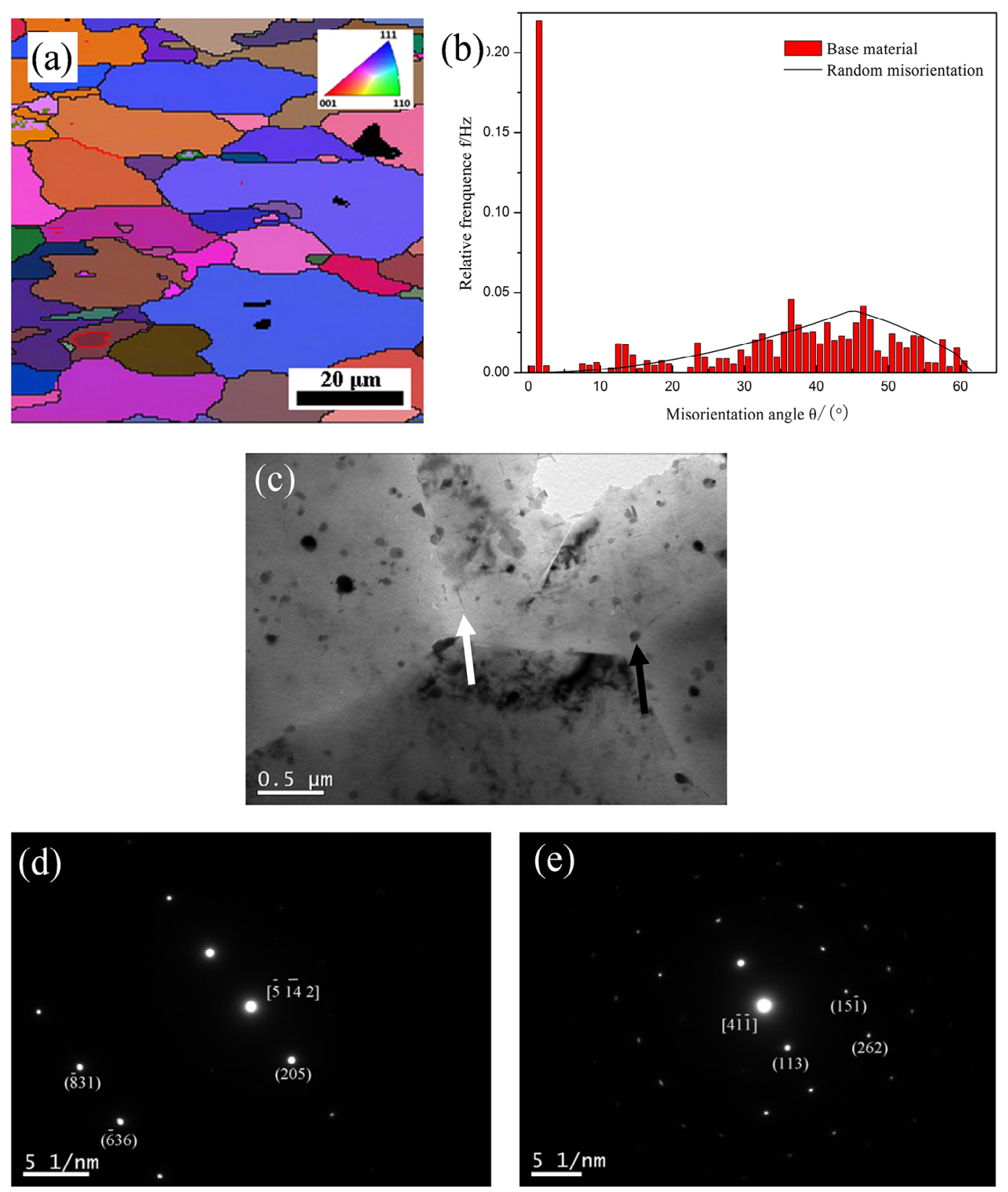

Figure 4. Microstructure of base material (a) grain morphology and grain boundary patterns; (b) distribution of grain misorientation; (c) grain boundary structure and morphology of precipitation phase; (d)electoral electron diffraction pattern for $\beta^{\prime \prime}$ phase; and (e) electoral electron diffraction pattern for $\beta$.

aluminum alloy, it needs longer time for the metallographic specimen to be corroded, and therefore corrosion pit appears in some localized sections. Note that equiaxed grains form in the advancing side(AS) of the nugget,as shown in Figure 5c.

\subsection{Microstructure of Nugget}

\subsubsection{Retreating Side}

The grain morphology of the retreating side of the nugget zone (region 1) is shown in Figure 6a. Compared with the base material, the nugget grain was refined with the average grain size of $5 \mu \mathrm{m}$. Owing to the shear stress introduced by the pin, the refined grain is elongated along the tangential direction of the pin with a "necklace" form (The white circles in Figure 6a and the red circles in Figure 6d represent the bead of the necklace, the black lines in Figure 6a and blue lines in Figure 6d represent the threading rope of the necklace). As shown in Figure 6c, the substructure of the lamellar dislocation wall formed at the retreating side, owing to the rotating extrusion effect of the pin. Aluminum and its alloys undergo plastic deformation under elevated temperatures with significant grain elongation and thinning 


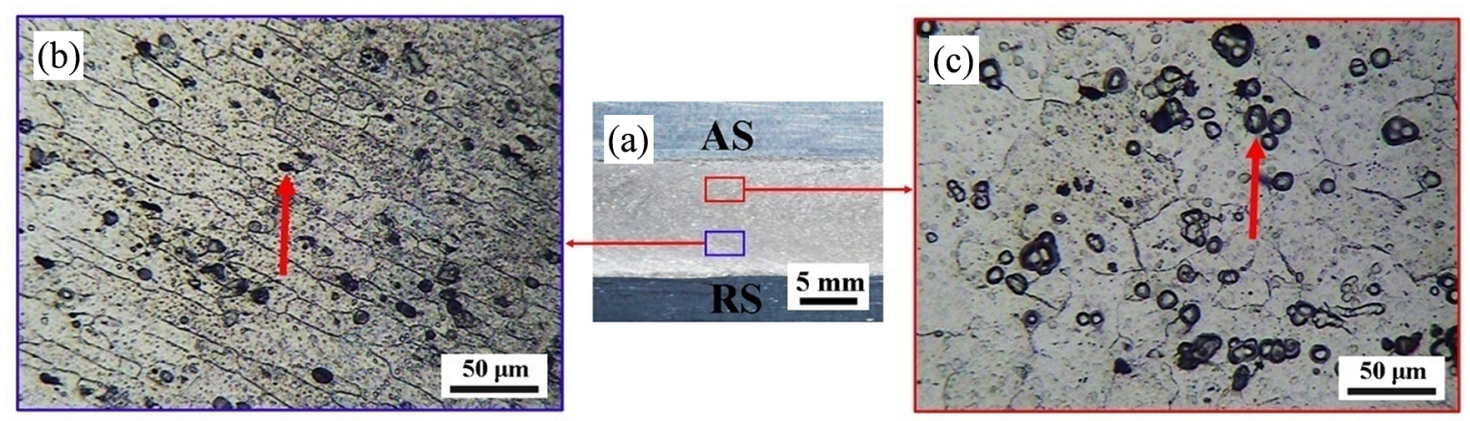

Figure 5. Microstructure of welding joint (a) retreating side, (b) macroscopic morphology and (c) advancing side (The black arrows in Figure5(a) and (b) indicate the corrosion pits)
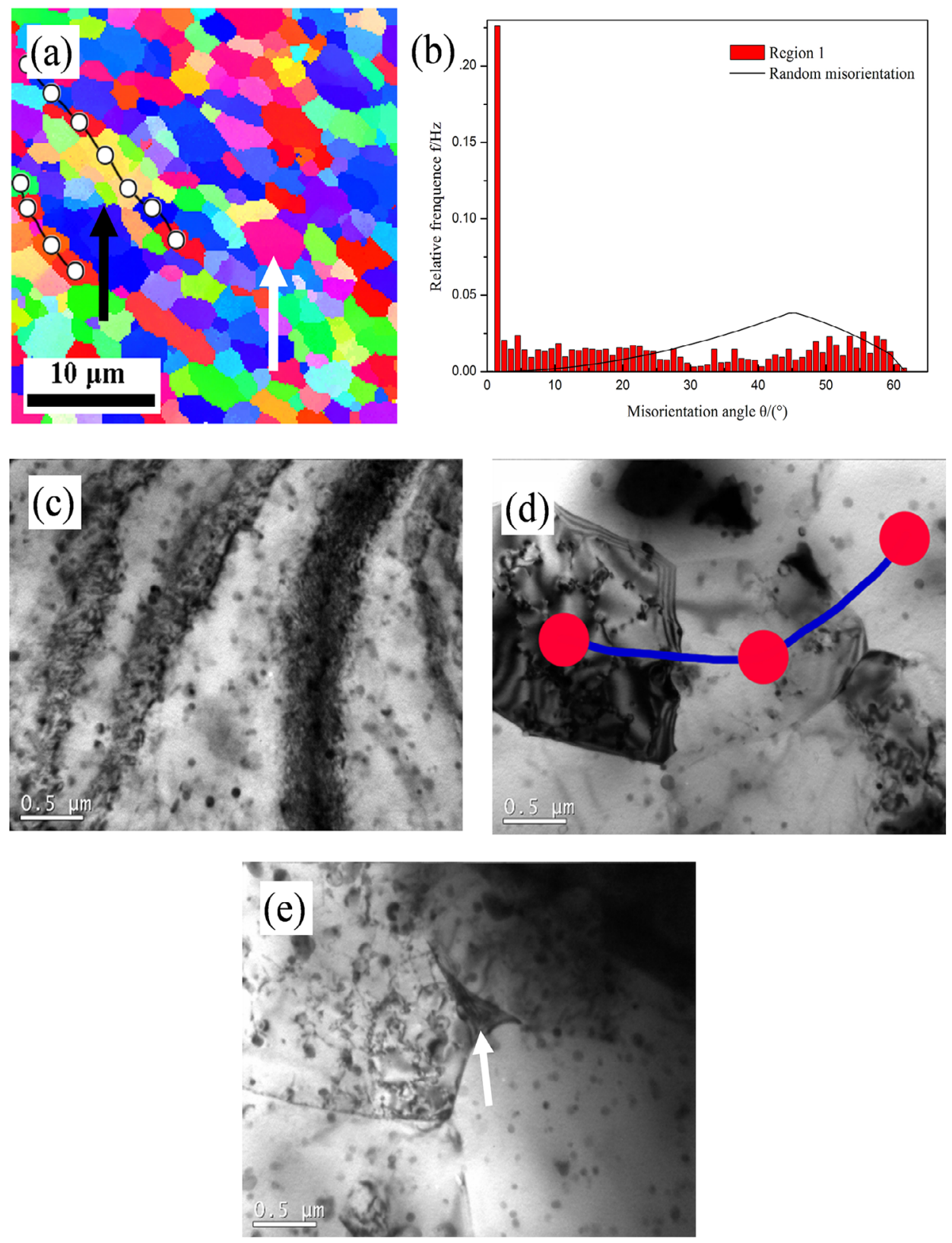

Figure 6. Microstructure of the retreating side of the nugget (a) Grain morphology and grain boundary patterns; (b) distribution of grain misorientation; (c) structure and morphology of the lamellar subgrain; (d) grain morphology of "necklace" form; and (e) deformed substructure in the triangular grain boundary. 
taking place, which leads to a dramatic increase of the grain boundary area. Motivated by the welding thermal cycle, geometric dynamic recrystallization occurs in the substructure of the lamellar grains ${ }^{16,17}$, leading to the lamellar array of grains. At the same time, with the plug and recombination of dislocations in the lamellar grains, subgrains consisting of small-angle grain boundaries are formed.

Under the action of thermal activation energy, subgrains with similar orientation differences are combined into alarge subgrain by rotation. In the process of rotation, part of the small-angle grain boundaries develop into large-angle grain boundaries, when the misorientation angles reach a critical value $\theta_{c}\left(\theta_{c} \approx 15^{\circ}\right)^{18}$, a lot of new crystal grains appear in "necklace" form within the lamellar grain, as shown in Figure $6 \mathrm{~d}$. The necklace structure is one of the main characteristics of discontinuous dynamic recrystallization. However, the necklace structure in the retreating side of nugget zone was obviously different from that of discontinuous dynamic recrystallization. The structure in the retreating side of the nugget zone was the accumulation of the necklace structure, as shown in Figure 6a, whereas the necklace structure appearing at the discontinuous dynamic recrystallization only occurred in the grain boundary ${ }^{19}$. Due to the dislocation accumulation and recombination, the increase of the grain boundary orientation angle and thus the formation of the large-angle grain boundary are often referred as continuous dynamic recrystallization ${ }^{20,21}$. As the continuous dynamic recrystallization occurs, part of the small angle grain boundaries are retained, resulting in the small angle grain boundary components of the nugget area increasing to $42.5 \%$, as shown in Figure $6 \mathrm{~b}$.

Under the effect of the welding thermal cycle, some grains grew obviously, about $7 \mu \mathrm{m}$, as indicated by the white arrow in Figure 6a. Smaller recrystallized (001)[100] cubic oriented grains between adjacent "necklace" grains were formed as indicated by the black arrow in Figure 6a. During the welding process, the hot deformation metal stores the distortion energy in the grain boundary and deformed substructure is first formed in the triangular grain boundary, where the dislocation density of (001)[100] cubic orientation, with simple dislocation configuration ${ }^{22}$ and low deformation energy storage ${ }^{23}$, was lower than that of the other substructure orientation. Second, based on the difference of the dislocation density and dislocation configuration of the cubic orientated substructure, the (001)[100] cubic orientation substructure achieves dynamic recovery due to the effect of the welding thermal cycle and further becomes the core of recrystallization. During the subsequent recrystallization process, the crystal nucleus grows up normally by swallowing other substructure and (001)[100] cubic oriented grains in the triangular grain boundaries finally appears. The above process of nucleation and growth is known as discontinuous dynamic recrystallization ${ }^{20-21}$. The structure evolution of the retreating side is as follows: lamellar substructure, lamellar structure, and "necklace" structure. As can be seen from Figures $6 \mathrm{c}-\mathrm{e}$, there are black-gray second-phase particles on the retreating side of the nugget core with consisting of $\mathrm{Al}$, $\mathrm{Mg}$, and Si elements at about $67.4 \%, 21.6 \%$ and $0.4 \%$ (mass fraction), respectively. It should be an $\mathrm{Mg}_{2} \mathrm{Si}$ phase ${ }^{24}$. The EBSD results also show that region 1 contains $\mathrm{Mg}_{2} \mathrm{Si}$ with a fraction of $4.78 \%$ (volume fraction). The metal in the nugget zone underwent large plastic deformation, resulting in the spheroidization of the second-phase particle morphology, which reduced its surfaceand surface energy. Therefore, $\mathrm{Mg}_{2} \mathrm{Si}$ presented granular distribution in the retreating side of nugget the zone ${ }^{25}$.

\subsubsection{Advancing Side}

The grain morphology on the advancing side of the nugget area, mainly consisting of equiaxed grains, was completely different from that on the retreating side and the distribution pattern of the "necklace" was not obvious. The proportion of large grain increases and in some areas, there were all large grains with showing a (111)[T10] shear orientation, as indicated by the red circle in Figure 7a. However, in other regions there were fine equiaxed grains with a (001)[100] cubic orientation as indicated by the green circle in Figure 7a. Due to the inhomogenous distribution of stress in the welding process, grains located in small stress areas underwent plastic deformation with a minimum orientation factorin the [T00] direction of the (111) face ${ }^{26}$. Therefore, the (111)[110] shear orientation grains first appeared with the dislocation motion, resulting in a large number of dislocations inside the grain. However, as shown in Figure 7c, the dislocation wall did not form and there was no recrystallization phenomenon. Due to the high degree of plastic deformation in the large stress area, the main deformation mechanism was the grain boundary slip and a lot of small(001)[100] cubic oriented grains were produced by recrystallization with a lower dislocation density, as shown in Figure 7d. As seen from Figures 7c and $7 \mathrm{~d}$, there were also black-gray second-phase particles on the advancing side of the nugget zone. It should be the $\mathrm{Mg}_{2} \mathrm{Si}$ phase ${ }^{24}$. The EBSD results also showed that zone 2 contained $\mathrm{Mg}_{2} \mathrm{Si}$ with a fraction of $6.45 \%$ (volume fraction)

According to the flow of viscoplastic metals in the FSW welding process, the viscoplastic metal flow first enters the retreating side, flows through the center of the nugget zone and finally reaches the advancing side ${ }^{27}$. Therefore, the plastic deformation of the advancing side of the nugget zone is less than that of the retreatingside and nugget zone. However, the results of EBSD showed that the fraction of medium and small angle grain boundaries on the advancing side was up to $52.8 \%$, as shown in Figure $7 \mathrm{~b}$.

The above phenomenon can be explained by the plasticity of the metal of the advancing side, so less distortion energy is stored in the grain boundary and intragranular grain, and only some of the grains achieved recrystallization while retaining small-angle grain boundaries. Next, the retreating 

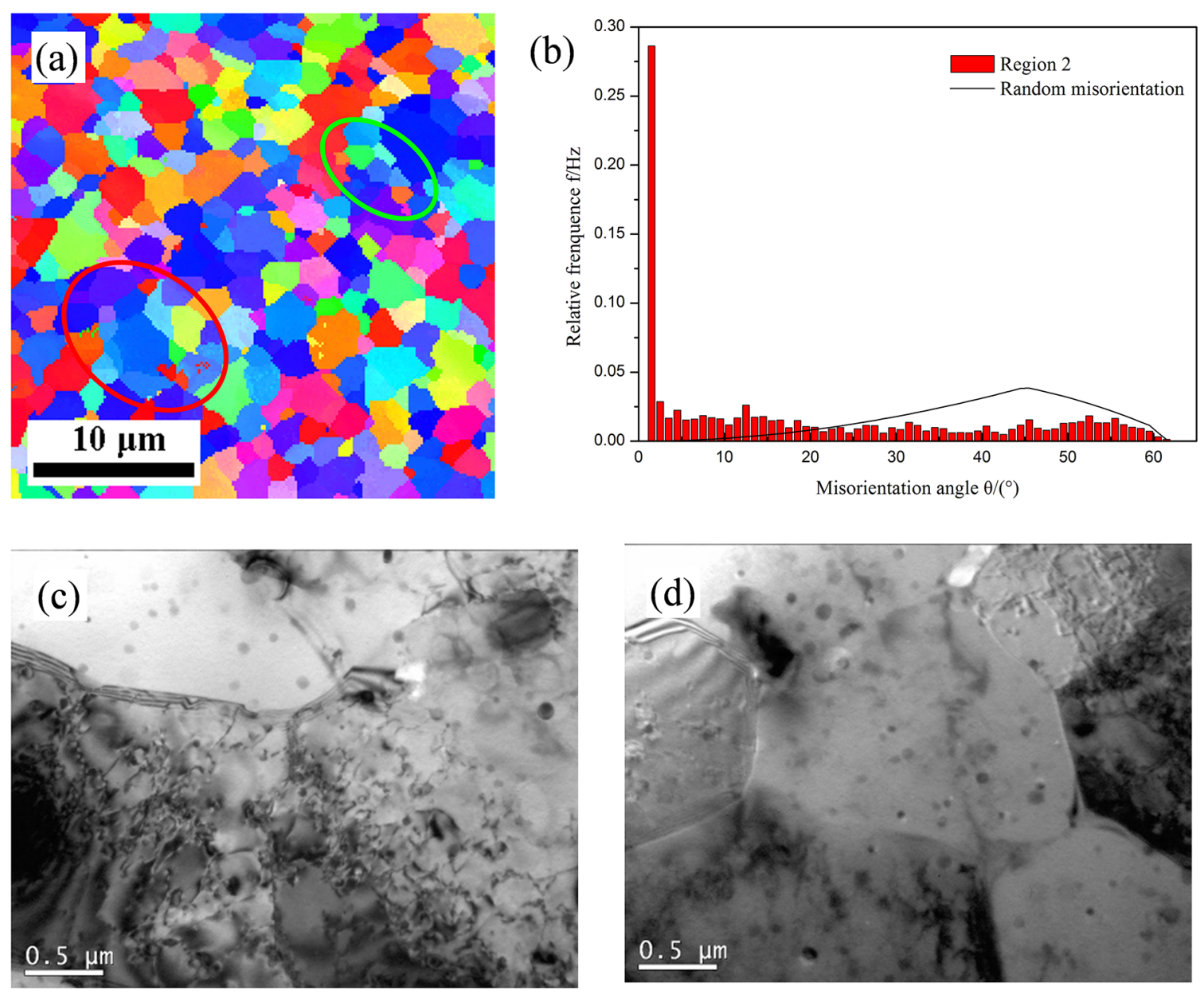

Figure 7. Microstructure of advancing side of the nugget. (a)Grain morphology and grain boundary patterns; (b) distribution of the grain misorientation;(c) structure and morphology of the coarse grain; and (d)structure and morphology of the fine grain.

side experienced large plastic deformation with high grain boundary storage energy and the temperature at the retreating side was higher than that of the advancing side during the welding process ${ }^{28}$, resulting in a high recrystallization degree of the retreating side and reduction of the small angle grain boundary components.

\subsection{Mechanical properties of base material and joint}

The mechanical properties test of the base material and joint specimen are shown in Figure 8.The tensile strength of the base material was $330 \mathrm{MPa}$ with a break elongation of $20 \%$. In addition, the tensile strength of the joint was $275 \mathrm{MPa}$ with a break elongation of $6 \%$ and the fracture position of the joint was at the advancing side of the nugget.

The tensile fracture morphology of the base material and joint are shown in Figure 9. It can be seen that the fractures were full of circular or ellipse dimples of varying sizes with more and deeper dimples in the base material. It can be seen from the analysis results of the tensile specimen

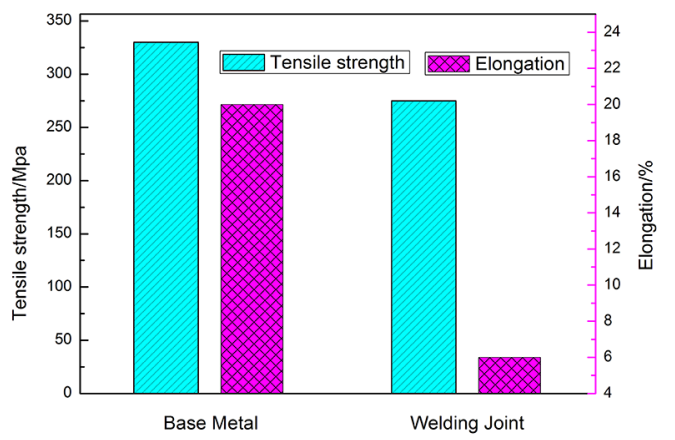

Figure 8. Tensile properties of base material and welding joint.

of the weld that the tensile fracture mode of the joint was a typical ductile fracture.

Figure 9a indicates that the fracture center of the base material was mainly composed of small equiaxial dimples. Compared with the base material fracture the size of the dimples in the joint fracture is large and shallow with flat appearance as shown in Figures 9b-9f. This was due to the uneven distribution of grain size in the advancing side of 

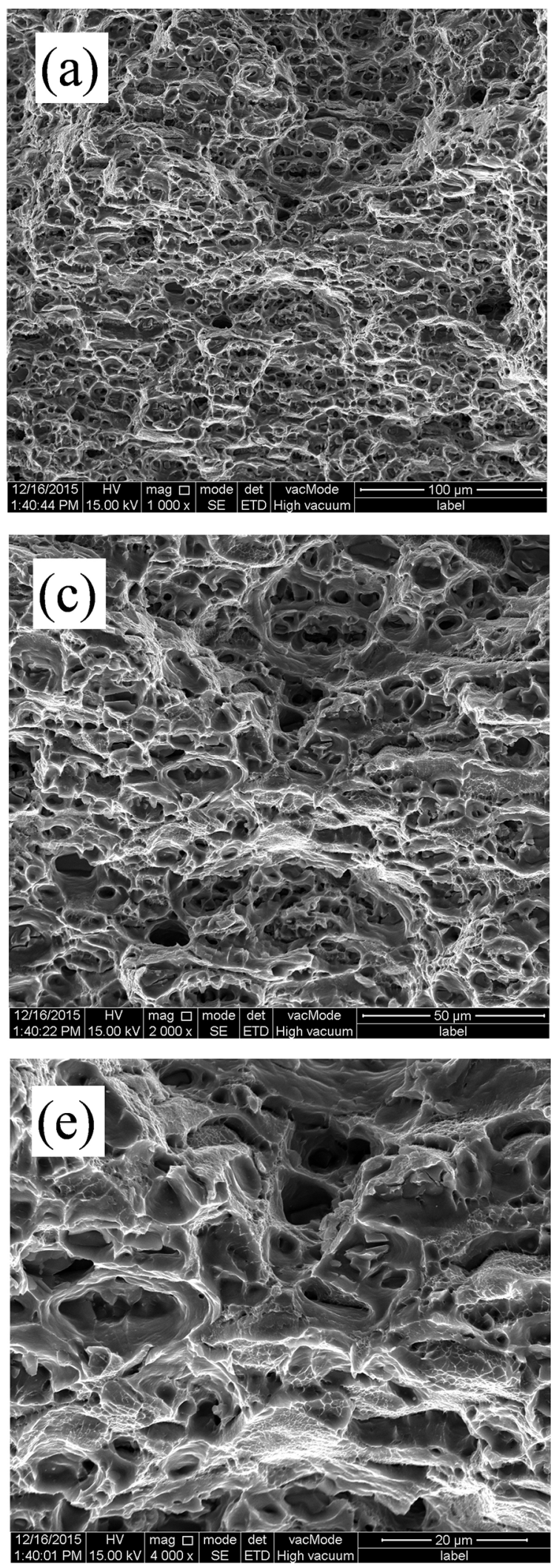
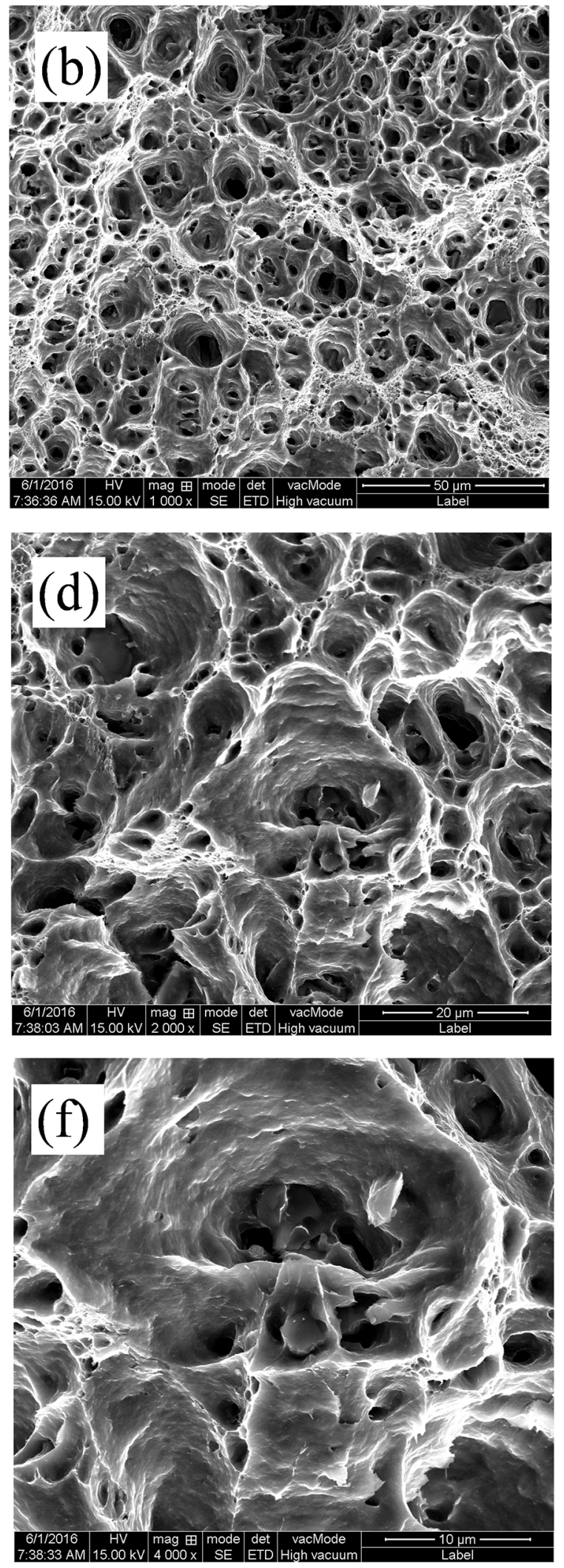

Figure 9. Analysis of the scanning electron microscope fracture of the base material and joint. (a) base material;(b) joint; (c and e)local magnification of the fracture of base material; ( $d$ and $f$ ) local magnification of the fracture of joint. 
the nugget and the large grain contained the second phase particles of $\mathrm{Mg}_{2} \mathrm{Si}$ witha (111)[T10] orientation. The face centered cubic metalorientationfactorin the [110] direction of (111) face was minimal ${ }^{26}$.

During the process of the tensile test, the plastic deformation of the large grain first occurred first and the intragranular dislocations were plugged up in the second phase. When the stress concentration reached the bonding strength between the $\mathrm{Mg}_{2} \mathrm{Si}$ phase and the aluminum body, the $\mathrm{Mg}_{2} \mathrm{Si}$ was separated from the interface of the body to form a microvoid, and the growth of the microvoid caused the internal necking of the specimen. However, the connection of adjacent microvoids led to a partial rupture. The traces left by the microvoid connections were the dimples on the fracture $^{29}$. This showed that the plasticity and elongation of joint were less than the base material and the fracture position of the joint was the advancing side.

\section{Conclusions}

1. The substructure of the lamellar dislocation wall is formed at the retreating side due to the shear stress introduced by the tool.

2. In the retreating side of the nugget zone, geometric dynamic recrystallization first occurred, appearing as a lamellar structure. With the pile-up and recombination of dislocations in the grains, subgrains were formed and the rotatation and merging of these subgrains due to the stress of the welding process resulted in the occurrence of continuous dynamic recrystallization. Finally, new recrystallized grains formed in the lamellar grains with presenting a necklace arrangement. Simultaneously, the coarse grain of the base material was refined.

3. The metal in the nugget zone underwent large plastic deformation, which resulted in the spheroidization of the second-phase particle morphology with $\mathrm{Mg}_{2} \mathrm{Si}$ presenting a granular distribution in the retreating side of the nugget zone.

4. During the welding process, the stress distribution was not uniform, leading to a large grain area and a small grain area in the advancing side. The (111) [T10] orientation grain in the advancing side of the nugget had the smallest orientation factor and intragranular dislocations were piled up in the second phase $\mathrm{Mg}_{2} \mathrm{Si}$, resulting in fracture. Thus, the mechanical properties of the advancing side became the weakest part of the joint.

\section{Acknowledgments}

This work was supported by major national science and technology projects under No.2012ZX04008011 and the fundamental research funds of Gansu province for higher education institutions.

Conflicts of Interest: The authors declares that there is no conflict of interest regarding the publication of this paper.

\section{References}

1. Liu W. Study on the Production Process of 6082 Aluminium Alloy Profiles for Ship. Aluminium Fabrication. 2001;24:19-22.

2. Su JQ, Nelson TW, Mishra R, Mahoney M. Microstructural investigation of friction stir welded 7050-T651 aluminium. Acta Materialia. 2003;51(3):713-729.

3. Ericsson M, Sandström R. Influence of welding speed on the fatigue of friction stir welds and comparison with MIG and TIG. International Journal of Fatigue. 2003;25(12):1379-1387.

4. Xu WF, Liu JH, Chen DL. Material flow and core/multishell structures in a friction stir welded aluminum alloy with embedded copper markers. Journal of Alloys \& Compounds. 2011;509(33):8449-8454.

5. Yuan GC, Liang CL, Liu H, Yuan Q. Crystal orientation in nugget zone of friction stir welded 5083 aluminum alloy plates. Transactions of the China Welding Institution. 2014;35(8):8084.

6. Suhuddin UFHR, Mironov S, Sato YS, Kokawa H. Grain structure and texture evolution during friction stir welding of thin 6016 aluminum alloy sheets. Materials Science \& Engineering: A 2010;527(7-8):1962-1969.

7. Zhang CC, Chang BH, Tao J, Zhang T. Microstructure evolution during friction stir welding of 2024 aluminum alloy. Transactions of the China Welding Institution. 2013;34(3):57-60.

8. Hou JC, Liu HJ, Zhao YQ. Influences of rotation speed on microstructures and mechanical properties of 6061-T6 aluminum alloy joints fabricated by self-reacting friction stir welding tool. International Journal of Advanced Manufacturing Technology. 2014;73(5-8):1073-1079.

9. Verma S, Meenu, Misra JP. Study on temperature distribution during Friction Stir Welding of 6082 aluminum alloy. Materialstoday: Proceedings. 2017;4(2 Pt A):1350-1356.

10. Tamadon A, Pons D, Sued K, Cuclas D. Development of Metallographic Etchants for the Microstructure Evolution of A6082-T6 BFSW Welds. Metals. 2017;7:423.

11. Peng Y, Shen C, Zhao Y, Chen Y. Comparison of Electrochemical Behaviors between FSW and MIG Joints for 6082 Aluminum Alloy. Rare Metal Materials and Engineering. 2017;46(2):344348 .

12. Mironov S, Sato YS, Kokawa H, Inoue H, Tsuge S. Structural response of superaustenitic stainless steel to friction stir welding. Acta Materialia. 2011;59(14):5472-5481.

13. Zhang F, Liu YF, Li JL, Li YJ, Wang MJ. Effect of Solution Treatment Temperature on Microstructure and Properties of 6181A Aluminum Alloy. Foundry Technology. 2017;5:10421046.

14. Gong WB, Tian HJ, Liu W, Wang YJ, Wang SJ. Mechanical properties change along the thickness direction of thick 
aluminium alloy 6082-T6 plate. Rare Materials and Engineering. 2012;41:854-857.

15. Zandbergen HW, Andersen SJ, Jansen J. Structure Determination of Mg5Si6 Particles in Al by Dynamic Electron Diffraction Studies. Science. 1997;277(5330):1221-1225.

16. Huang K, Logé RE. A review of dynamic recrystallization phenomena in metallic materials. Materials \& Design. 2016;111:548-574.

17. Song KH, Fujii H, Nakata K. Effect of welding speed on microstructural and mechanical properties of friction stir welded Inconel 600. Materials \& Design. 2009;30(10):3972-3978.

18. Gourdet S, Montheillet F. An experimental study of the recrystallization mechanism during hot deformation of aluminium. Materials Science \& Engineering: A . 2000;283(1-2):274-288.

19. Ponge D, Gottstein G. Necklace formation during dynamic recrystallization: mechanisms and impact on flow behavior. Acta Materialia. 1998;46(1):69-80.

20. Jata KV, Semiatin SL. Continuous dynamic recrystallization during friction stir welding of high strength aluminum alloys. Scripta Materialia. 2000;43(8):743-749.

21. McNelley TR, Swaminathan S, Su JQ. Recrystallization mechanisms during friction stir welding/processing of aluminum alloys. Scripta Materialia. 2008;58(5):349-354.

22. Mao WM. Crystallographic Texture and Anisotropy of Metallic Materials. Beijing: Science Press; 2002. p. 116-117.
23. Etter AL, Mathon MH, Baudin T, Branger V, Penelle R. Influence of the cold rolled reduction on the stored energy and the recrystallization texture in a Fe-53\%Ni alloy. Scripta Materialia. 2002;46(4):311-317.

24. Tian RZ, Wang ZT. Aluminum Alloy and its Processing Handbook. Changsha: Central South University Press; 2007. p. 250-253.

25. Frigaard Ø, Grong Ø, Midling OT. A process model for friction stir welding of age hardening aluminum alloys. Metallurgical \& Materials Transactions A. 2001;32(5):1189-1200.

26. Canova GR, Kocks UF, Jonas JJ. Theory of torsion texture development. Acta Metallurgica. 1984;32(2):211-226.

27. Gratecap F, Girard M, Marya S, Racineux G. Exploring material flow in friction stir welding: Tool eccentricity and formation of banded structures. International Journal of Material Forming. 2012;5(2):99-107.

28. Du YF, Bai JB, Tian ZJ, Zhang Y. Investigation on threedimensional real coupling numerical simulation of temperature field of friction stir welding of 2219 aluminum alloy. Transactions of the China Welding Institution. 2014;35(8):57-60, 70.

29. Wang XJ, Sun GP, Zhang J, Xu C, LI SW, Niu Y. Effects of heat treatment after welding on friction stir welding joints of highstrength aluminium alloy. The Chinese Journal of Nonferrous Metals. 2009;19(3):484-490. 